\title{
Transport and structure within the Antarctic Circumpolar Current to the north of South Georgia
}

\author{
P. N. Trathan, M. A. Brandon, ${ }^{1}$ and E. J. Murphy \\ BioSciences Division, British Antarctic Survey, Cambridge, U.K.
}

\author{
S. E. Thorpe \\ School of Environmental Sciences, University of East Anglia, Norwich, U.K.
}

\begin{abstract}
The Antarctic Circumpolar Current (ACC) crosses rugged topography to the north of South Georgia. In this region the subsurface expression of the Polar Front (PF) is generally thought to occur north of the Maurice Ewing Bank (MEB) close to the Subantarctic Front (SAF). However, in January 1996 the $\mathrm{PF}$ was south of the bank, separate from the SAF, in a position where it was most likely constrained by local bathymetry. High rates of transport ( $25 \mathrm{~Sv}$ eastward) were present at the $\mathrm{PF}$, consistent with previous estimates for this current core. High transport rates (20 Sv westward) were also present along the northern shelf of South Georgia close to where the southern ACC Front (sACCF) has previously been reported. During our occupation, the SACCF was not encountered as it probably lay outside the survey area. Comparisons with recent circumpolar analyses emphasise the potential for variability in the region.
\end{abstract}

\section{Introduction}

The ACC is constrained in many regions by major topographic features. In the southwest Atlantic it crosses a region of rugged topography known as the Scotia Arc. This feature bounds three sides of the Scotia Sea and runs continuously from the Antarctic Peninsula to the Patagonian Shelf. Over the north of the Arc close to South Georgia two of the deep fronts within the ACC exit the Scotia Sea and pass into the south Atlantic; these are the PF and the SACCF. Levels of variability in the location of these fronts are not known, however the rugged bathymetry of the region would suggest that they are probably geographically constrained [cf. Moore et al., 1999]. This study presents results from a hydrographic transect carried out to the northwest of South Georgia that crossed the PF [Orsi et al., 1995; Trathan et al., 1997] and which provides details about transport and structure in the region.

\footnotetext{
${ }^{1}$ Now at Earth Sciences Department, The Open University, Milton Keynes, U.K.
}

Copyright 2000 by the American Geophysical Union.

Paper number 1999GL011131.

0094-8276/00/1999GL011131\$05.00

\section{Survey Design}

The transect (Figure 1) was carried out in January 1996 during cruise JR11 of the RRS James Clark Ross. It began north of the MEB $\left(47^{\circ} 59^{\prime} \mathrm{S}, 43^{\circ} 16^{\prime} \mathrm{W}\right)$ and ran across the Falkland Trough towards the continental shelf of South Georgia $\left(53^{\circ} 52^{\prime} \mathrm{S}, 38^{\circ} 40^{\prime} \mathrm{W}\right)$. The transect consisted of 22 conductivity-temperature-depth (CTD) stations with a nominal spacing of $35 \mathrm{~km}$; all stations sampled the surface waters, with alternating stations sampling to near-bottom. At each station a Research Development Instruments hull-mounted $150 \mathrm{kHz}$ acoustic Doppler current profiler (ADCP) was used to sample absolute current velocities at the surface.

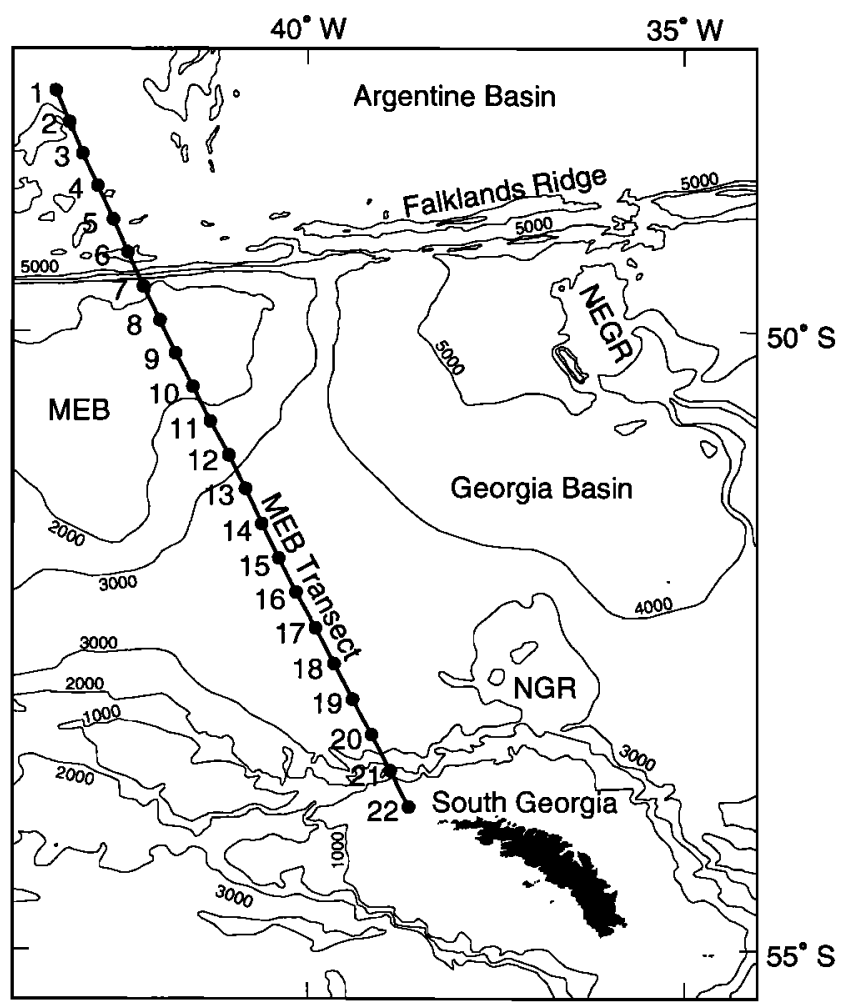

Figure 1. Station positions (circles) along the MEB transect; Maurice Ewing Bank (MEB), North Georgia Rise (NGR), Northeast Georgia Rise (NEGR). 

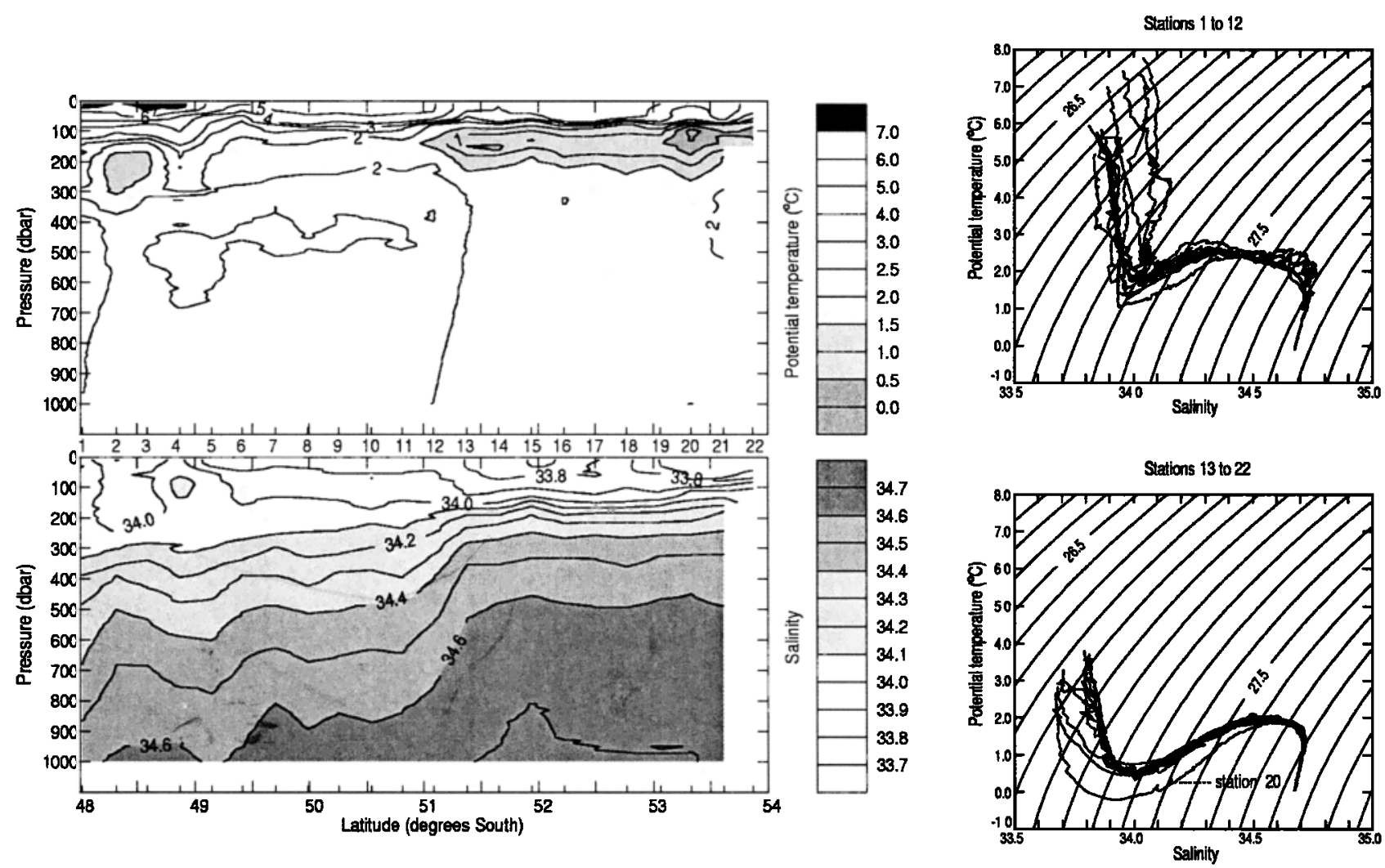

Figure 2. Potential temperature and salinity along the MEB transect. (a) Potential temperature (degrees Celsius) section (station positions are indicated by small ticks on the horizontal axis); (b) salinity section; (c) potential temperature plotted against salinity for PFZ stations (stations 1 to 12); and for (d) AZ stations (stations 13 to 22 ).

\section{Results}

Plots of potential temperature (Figure $2 \mathrm{a}$ ) and salinity (Figure 2b) for the upper 1000 dbar show that the first station (station 1) was south of the SAF, inside the Polar Frontal Zone (PFZ). This was most apparent in salinity (Figure 2b), a better indicator of the SAF than temperature [Whitworth and Nowlin, 1987]. Below 100 dbar, where salinity largely determines density, the isopycnal gradients showed strong density differences consistent with the proximity of the SAF.

Strong water property gradients were also evident further south where potential temperature (Figure 2a) revealed the $\mathrm{PF}$ at $51^{\circ} 15^{\prime} \mathrm{S}$. This was nominally between stations 12 and 13 on the southern edge of the MEB. At this position the PF was also evident from the gradient of isopycnals in the potential density, with the steepest gradient corresponding to the PF.

Potential temperature/salinity plots (Figure 2c,d) for the 22 stations revealed strong water property differences either side of the MEB. To the north and over the bank, stations 1 to 12 (Figure 2c) were identified as within the PFZ, while to the south stations 13 to 22 (Figure 2d) were identified as within the Antarctic Zone (AZ) [cf. Orsi et al., 1995]. In the PFZ the depth, temperature and salinity of the near-surface temperature minimum varied with latitude, it being deeper, warmer and more saline towards the north (Figure 2a). Thus, at stations 1 and 4 the near-surface minimum was only weakly defined at $300 \mathrm{dbar}$, having a temperature of $2.0^{\circ} \mathrm{C}$ and a salinity of 34.05 (Figure $2 \mathrm{a}, \mathrm{b}$ ). In comparison at station 12 , the most southerly station within the PFZ, the near-surface minimum was strongly defined at $150 \mathrm{dbar}$, being both cooler $\left(1.5^{\circ} \mathrm{C}\right)$ and fresher (33.95) (Figure 2a,b). Station 12 was similar to that described at the PF by Gordon et al., [1977] and was consistent with a frontal location.

Within the PFZ a mesoscale feature existed that was identified by a cooler $\left(1.0\right.$ to $\left.1.5^{\circ} \mathrm{C}\right)$ and fresher (33.90) near-surface temperature minimum. This feature occurred towards the north of the transect at stations 2 and 3 (Figure 2a,b) where the water properties resembled the most southerly station in the regime (station 12); however, the near-surface minimum at stations 2 and 3 was not as strongly defined as that at the PF.

Variability was also evident within the AZ. In particular an anomalous station (Figure 2d) occurred at the southern end of the transect (station 20). At the near-surface temperature minimum (100 dbar), this station was cooler $\left(-0.2^{\circ} \mathrm{C}\right)$ and fresher $(33.93)$ than other stations in the AZ. Surface anomalies (Figure 2d) at adjacent stations (stations 18 to 22) were also evident as local mixing with water of properties similar to those at station 20.

As structure within the ACC extends to the deepest depths, the common reference level between sta- 


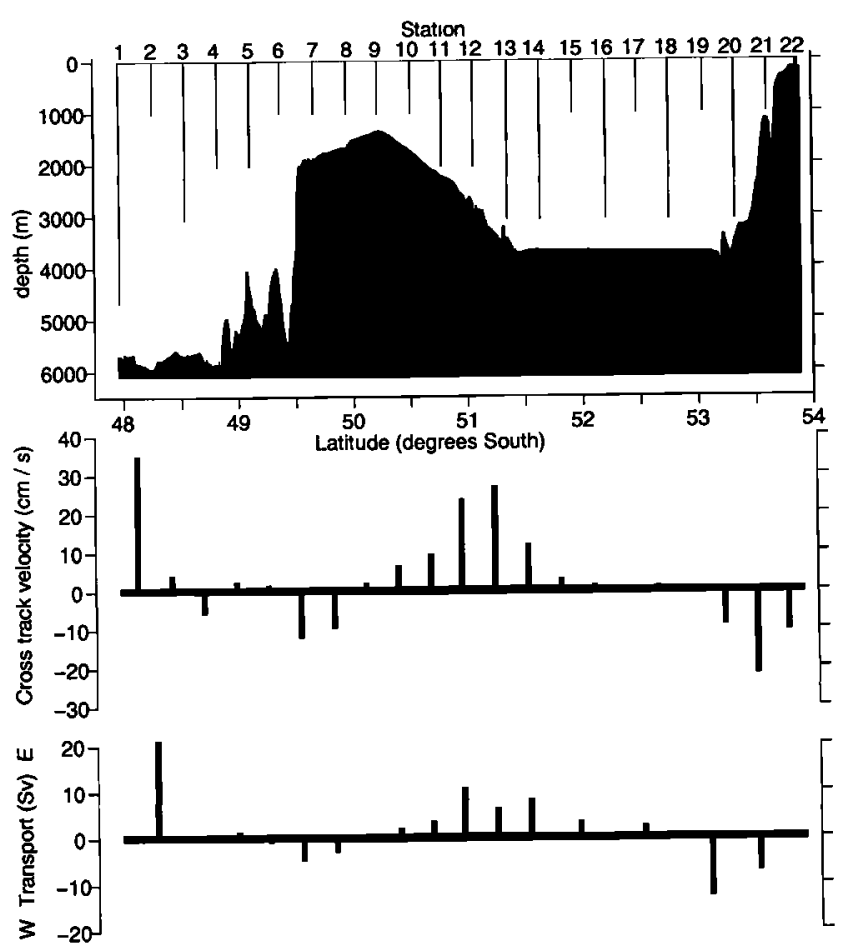

Figure 3. (a) Bathymetry along the MEB transect, CTD depths are indicated by vertical lines. (b) Absolute velocity $\left(\mathrm{cm} \mathrm{s}^{-1}\right)$ for station-pairs, calculated from the depth-averaged orthogonal component of ADCP data below $100 \mathrm{~m}$ and better than $25 \%$ good. (c) Estimated volume transport (Sverdrup; $1 \mathrm{~Sv}=10^{6} \mathrm{~m}^{3} \mathrm{~s}^{-1}$ ) calculated from geostrophic estimates that have been adjusted against absolute ADCP velocity data. East is positive.

tions (1000 dbar) is inadequate to characterise net volume transport. Therefore in this study we have calculated net transport using geostrophic velocities that have been adjusted against absolute velocity estimates derived from on-station ADCP current data (Figure 3). To make this adjustment we first calculated the orthogonal velocity component from the ADCP data. For this, a lower depth limit was used above which data were better than $25 \%$ good. This lower limit varied with station, but for stations 1 to 21 (off shelf) the average was 324 $\mathrm{m}$ (range 240 to $384 \mathrm{~m}$ ). An upper depth limit was also used; this was chosen to minimise surface affects and was arbitrarily set at $100 \mathrm{~m}$. The ADCP estimates of orthogonal velocity were depth-averaged for each station. These estimates were then averaged between adjacent station-pairs (Figure 3b) and used to adjust geostrophic velocities depth-averaged over the same depth range. The resulting values were then used as an estimate of error at the geostrophic reference level of no motion so that new transport estimates (Figure $3 \mathrm{c}$ ) could be derived. The level of no motion used in the geostrophic calculations was the bottom of the cast; however to ensure that all deep casts were fully utilized, stations 2 , 15,17 and 19 (all to $1000 \mathrm{dbar}$ ) were excluded. Over the shelf where depths were less than $250 \mathrm{~m}$, the ADCP data estimated velocities to the bottom.
The ADCP absolute velocities for station-pairs (Figure $3 \mathrm{~b}$ ) emphasise the strong eastward flow at the northern edge of the PFZ and at the PF. They also emphasise the relatively still water in the Georgia Basin and the strong westward flow along the steep northern face of the MEB and along the shelf-edge at South Georgia. The net transport estimates (Figure 3c) show a similar pattern, with approximately $21 \mathrm{~Sv}$ in an eastward direction above 3000 dbar just south of the SAF and approximately $25 \mathrm{~Sv}$ in an eastward direction above 2000 dbar at the PF. The other strong flows in the section indicate net westward transport of $8 \mathrm{~Sv}$ along the north of the MEB and $20 \mathrm{~Sv}$ along the northern shelf at South Georgia. The volume transport at the PF was comparable with the results from the Melville SAVE section (approximately $20 \mathrm{~Sv}$ ) reported by Orsi et al., [1995].

\section{Discussion}

The SAF is the most northerly of the circumpolar deep-reaching current cores in the ACC. It was not sampled during this transect, however it is likely that it lay just north of the transect close to a position previously reported by Peterson and Whitworth, [1989] and Whitworth et al., [1991]. Evidence that this was the case can be seen in the water properties at the northern end of the section which showed steepening gradients in salinity and density. Further evidence also comes from the high ADCP current velocities at station 1 which showed an eastward component of approximately $63 \mathrm{~cm} \mathrm{~s}^{-1}$. Such velocities are consistent with the frontal velocities for this region $\left(75 \mathrm{~cm} \mathrm{~s}^{-1}\right)$ that have been reported previously [Whitworth et al., 1991]. Thus, the likely position of the SAF during cruise JR11 was consistent with that of previous reports.

In contrast, the location of the PF differed from that previously reported by Peterson and Whitworth, [1989], Whitworth et al., [1991] and Orsi et al., [1995]. During our study, the PF was separated from the SAF by the MEB and occurred on the southern edge of the bank at a location close to that reported by Trathan et al., [1997]. This southern location has also been identified by Moore et al., [1997; 1999] who reported this location was where the surface expression was most commonly observed. Moore et al., [1997] suggested that the surface and subsurface expressions of the PF may become separated; however, it is evident from our results that they were tightly coupled during cruise JR11.

The apparent southern position of the PF could have resulted from the presence of mesoscale features associated with the main axis of the PF. As such the southern manifestation could be the consequence of southerly intrusions of warmer, northern water pushing the PF southwards to form a meander or core ring. However, as the flow in this area appears to be constrained by bathymetry (Figure 3), it is unlikely that it freely meanders. Thus, topographic steering appears to be an important factor in the location of the $\mathrm{PF}$ in this region, 
a point also highlighted by Moore et al., [1997]. Given the consistency of the position of the surface and subsurface expressions of the PF, not only in 1994 [Trathan et al., 1997] but also in 1996 (this study), it is plausible that the dominant path through the region could be to the south of the MEB.

High levels of mesoscale variability have been documented within the PFZ, including reports of frontal meanders and core rings [e.g. Peterson and Whitworth, [1989]. During JR11, mesoscale variability was also evident to the north of the MEB. At this location a westward movement of water was recorded between stations 6 and 7 (approximately $49^{\circ} 30 \mathrm{~S}$ ). This flow of water could have left the Georgia Basin to the east of the MEB, possibly as a westward branch of the jet associated with the PF (cf. the near-surface temperature minimum at stations 2 and 3 with that at station 12). This flow could be related to the deep westward movement described by Whitworth et al., [1991] who reported deep flows of Weddell Sea water along the northern edge of the MEB. Such a situation would be consistent with suggestions made by Peterson [1986] who noted that the bathymetry of the region exerts a strong influence upon the upper-ocean currents.

During JR11, variability was also evident within the $\mathrm{AZ}$ to the north of South Georgia (stations 18 to 22) at a location previously identified by Trathan et al., [1997]. This area has been identified by Orsi et al., [1995] as the location where the SACCF (the southern-most of the ACC deep reaching current cores) extends northwest of South Georgia. The property indicators used to describe waters from south of the SACCF suggest that salinities of approximately 34.1 should be expected at the near-surface temperature minimum [Orsi et al., 1995]. However, the salinities at station 20 were considerably fresher (33.9) than this (Figure 2d), suggesting that this water was inconsistent with that from south of the sACCF. Thus, it is plausible that during JR11 the position of the SACCF was east of that identified by Orsi et al., [1995] and that the variability observed at stations 18 to 22 was associated with local modification at South Georgia [cf. Brandon et al., in press].

\section{Conclusion}

Our results provide information for a region of sparse data. They show that in January 1996 the PF was south of the MEB, separate from the SAF north of the bank. The PF was close to the location recorded by Trathan et al., [1997], who reported the only other recent occupation of the area. The results show that the climatological position of the PF is not fully determined for this region. They show that during January 1996 the surface and subsurface expressions of the PF were in close proximity [cf. Moore et al., 1997], suggesting that further information about the degree and persistence of separation would be useful. Further south, the results indicate that a more detailed examination of the character and location of the SACCF to the north of South Georgia would also be worthwhile.

\section{References}

Brandon, M. A., E. J. Murphy, P. N. Trathan, and D. G. Bone, Physical oceanographic conditions to the north west of the sub-Antarctic island of South Georgia, J. Geophys. Res., in press.

Gordon, A. L., D. T. Georgi, and H. W. Taylor, Antarctic Polar Front Zone in the western Scotia Sea - summer 1975, J. Phys. Oceanogr., 7, 309-328, 1977.

Moore, J. K., M. R. Abbott, and J. G. Richman, Variability in the location of the Antarctic Polar Front $\left(90^{\circ}-20^{\circ} \mathrm{W}\right)$ from satellite sea surface temperature data, J. Geophys. Res., 102, 27825-27833, 1997.

Moore, J. K., M. R. Abbott, and J. G. Richman, Location and dynamics of the Antarctic Polar Front from satellite sea surface temperature data, J. Geophys. Res., 104, 3059-3073, 1999.

Orsi, A. H., T. Whitworth III, and W. D. Nowlin Jr., On the meridional extent of the Antarctic Circumpolar Current, Deep-Sea Res., 42, 641-673, 1995.

Peterson, R. G., Abyssal boundary current studies deployment cruise, Antarctic J. of the U. S., 5, 125-127, 1986.

Peterson, R. G., and T. Whitworth III, The Subantarctic and Polar Fronts in relation to deep water masses through the southwestern Atlantic, J. Geophys. Res., 94, 1081710838, 1989.

Trathan, P. N., M. A. Brandon, and E. J. Murphy, Characterisation of the Antarctic Polar Frontal Zone to the north of South Georgia in summer 1994, J. Geophys. Res., 102, 10483-10497, 1997.

Whitworth III, T., and W. D. Nowlin Jr., Water masses and currents of the Southern Ocean at the Greenwich meridian, J. Geophys. Res., 92, 6462-6476, 1987.

Whitworth III, T., W. D. Nowlin Jr., R. D. Pillsbury, M. I. Moore, and R. F. Weiss, Observations of the Antarctic Circumpolar Current and deep boundary current in the southwest Atlantic, J. Geophys. Res., 96, 15105-15118, 1991.

M. A. Brandon, E. J. Murphy, P. N. Trathan, British Antarctic Survey, High Cross, Madingley Road, Cambridge CB3 0ET, UK (e-mail: p.trathan@bas.ac.uk)

S. E. Thorpe, School of Environmental Sciences, University of East Anglia, Norwich, U.K.

(Received October 24, 1999; revised March 15, 2000; accepted May 5, 2000.) 